\title{
Patient preferences in Italy: health state utilities associated with attributes of weekly injection devices for treatment of type 2 diabetes
}

This article was published in the following Dove Press journal:

Patient Preference and Adherence

\author{
Louis S Matza' \\ Kristina S Boye ${ }^{2}$ \\ Jessica B Jordan' \\ Kirsi Norrbacka ${ }^{3}$ \\ Raffaella Gentilella ${ }^{4}$ \\ Amara R Tiebout ${ }^{\prime}$ \\ Chantelle Browne ${ }^{5}$ \\ Marco Orsini Federici ${ }^{4}$ \\ Giovanni Biricolti ${ }^{4}$ \\ Katie D Stewart' \\ 'Patient-Centered Research, Evidera, \\ Bethesda, MD, USA; ${ }^{2}$ Eli Lilly and \\ Company, Indianapolis, IN, USA; ${ }^{3} \mathrm{Eli}$ \\ Lilly and Company, Helsinki, Finland; \\ ${ }^{4}$ Eli Lilly and Company, Florence, Italy; \\ ${ }^{5}$ Modeling and Simulation, Evidera, \\ London, UK
}

Correspondence: Louis S Matza Patient-Centered Research, Evidera, 7101 Wisconsin Avenue, Suite 1400 Bethesda, MD 208I4, USA

$\mathrm{Tel}+\mathrm{I} 3016647263$

Fax +I 30I 6549864

Email louis.matza@evidera.com
Objectives: Several glucagon-like peptide-1 receptor agonists are administered as weekly injections for treatment of type 2 diabetes (T2D). These medications vary in their injection processes, and a recent study in the UK found that these differences had an impact on patient preference and health state utilities. The purpose of this study was to replicate the UK study in Italy to examine preferences of an Italian patient sample, while allowing for comparison between utilities in the UK and Italy.

Materials and methods: Participants with T2D in Italy valued health states in time trade-off interviews. All health states had the same description of T2D, but differed in description of the treatment process. As in the original UK study, the first health state described an oral treatment regimen, while additional health states added a weekly injection. The injection health states differed in three injection-related attributes: requirements for reconstituting the medication, waiting during medication preparation, and needle handling.

Results: Interviews were completed by 238 patients ( $58.8 \%$ male; mean age $=60.2$ years; 118 from Milan, 120 from Rome). The oral treatment health state had a mean (SD) utility of 0.90 (0.10). The injection health states had significantly $(p<0.0001)$ lower utilities, which ranged from 0.87 (requirements for reconstitution, waiting, and handling) to 0.89 (weekly injection with none of these requirements). Differences in health state utility scores suggest that each administration requirement was associated with a disutility (ie, negative utility difference): -0.006 (reconstitution), -0.006 (needle handling), -0.011 (reconstitution, needle handling), and -0.022 (reconstitution, waiting, needle handling).

Conclusion: Disutilities associated with the injection device characteristics were similar to those reported with the UK sample. Results suggest that injection device attributes may be important to some patients with $\mathrm{T} 2 \mathrm{D}$, and it may be useful for clinicians to consider these attributes when choosing medication for patients initiating these weekly treatments.

Keywords: utility, type 2 diabetes, injection process, GLP-1 receptor agonist, time trade-off, weekly injection, Italy, injection device

\section{Introduction}

Health state utility assessments can provide insight into patient preferences among treatment options. Choice-based preference elicitation methods including time trade-off (TTO) and standard gamble procedures yield utility values representing the strength of preference for health states. ${ }^{1,2}$ These utilities may be used to calculate quality-adjusted life years (QALYs) in cost-utility analyses (CUAs) examining and comparing the value of pharmaceutical treatments. ${ }^{3}$ Although CUAs are often used to guide decisions on health care resource allocation in a wide range of geographical regions, the utilities used 
as inputs in these models are usually estimated in northern Europe, most frequently the United Kingdom.

Italy is one example of a country where CUAs often use utilities derived from preferences of patients or general population respondents in other countries including the UK. ${ }^{4-7}$ However, little is known about the extent to which health state preferences in Italy may differ from those in the UK. Some studies have derived utilities using the EQ-5D in multiple countries including Italy. ${ }^{8-10}$ While these studies allow for comparisons across countries, the preferences and resulting utilities are not directly comparable because the EQ-5D values are based on patients' ratings of their own unique health, and there could be substantial variation in patient sample characteristics across countries. No studies were located that provide the opportunity for comparing utility values for the same health states in Italy and other countries.

The current study addresses this issue by replicating a UK health state utility valuation in a sample of Italian patients, using the same methods and health states so that results would be directly comparable between countries. This replication was designed to provide insight into whether UK patient preferences may be generalizable to a southern European country such as Italy. The UK study completed in 2015 focused on patient preferences related to treatment process attributes of weekly glucagon-like peptide-1 (GLP-1) receptor agonists, ${ }^{11}$ which are injectable medications that are often recommended as part of combination therapy for type 2 diabetes (T2D) when oral medication does not result in sufficient glycemic control. ${ }^{12-15}$

Despite similarities in efficacy and safety, ${ }^{12,16,17}$ the weekly GLP-1 receptor agonists differ in terms of injection treatment process attributes. Therefore, this study focused on preferences and utility differences associated with three treatment-related attributes that vary among these treatments: 1) requirements for reconstitution (ie, mixing the medication) prior to injection, 2) waiting time required prior to the injection, and 3) whether patients are required to handle the injection needle. The first two attributes were hypothesized to be important to patients who prioritize ease of administration, while the third attribute is considered to be an important safety issue. ${ }^{18,19}$ The UK study found that these treatment process attributes had a quantifiable impact on patient preference. ${ }^{11}$

In sum, the current study had three goals. First, TTO utility elicitation interviews were conducted to provide insight into patient preferences among weekly GLP-1 receptor agonists injection device attributes in Italy. Second, the interviews were designed to yield utility scores that could be useful in economic modeling of weekly GLP-1 receptor agonists in Italy. Third, by enabling comparison of current results to those of the original UK utility valuation study, the current replication can provide insight into potential geographic differences in treatment preference and utility scores.

\section{Materials and methods Overview of study design}

This vignette-based study elicited patient preferences and estimated health state utilities for injection process attributes of weekly GLP-1 receptor agonists in a sample of patients with T2D in Italy (Milan and Rome) in March and April 2017. This was a replication of a previous utility valuation study conducted in the UK in 2015. ${ }^{11}$ Other than the translation of study materials into Italian, health states and utility elicitation methods were the same as those previously described for the UK study. ${ }^{11}$ Health state descriptions (often called "health states" or vignettes) drafted for the original UK study were valued by patients in TTO interviews with a 20 -year time horizon. These methods were based on those of two previous studies that were conducted to estimate utilities associated with attributes of injectable treatments for T2D. ${ }^{20,21}$ The utilities reported in these previous publications have been used in multiple published CUAs of treatments for T2D. ${ }^{22-25}$

Utilities were estimated using health state descriptions because the vignette-based approach is well-suited for isolating the impact of specific treatment-related attributes on utility. Although generic preference-based measures such as the EQ-5D are often recommended for estimating utilities, ${ }^{26}$ these standardized instruments do not specifically assess the impact of treatment process or treatment convenience. Therefore, they are unlikely to be sensitive to differences in the injection device attributes that were the focus of this study.

\section{Health state development}

The health states that were valued in this Italian study were a translated version of health states developed for the previous UK study. ${ }^{11}$ For the UK study, the health states were drafted and refined in five steps. First, health states from two previously published studies were adapted for the introductory description of $\mathrm{T} 2 \mathrm{D}$ appearing at the beginning of every health state..$^{20,21}$ Second, a literature search was performed to identify attributes of injection devices that were likely to be important to patients and differentiate the weekly GLP-1 receptor agonists. ${ }^{27-29}$ Third, interviews with four clinicians (all with MD degrees and research/clinical experience with T2D) were conducted to finalize the list of injection device attributes and inform the development of 
health state text. Fourth, instructions for use of the available weekly GLP-1 receptor agonist devices were used to finalize details of the health states, including the information in the device display page described below. ${ }^{27-29}$ Fifth, a pilot study was conducted with patients $(\mathrm{N}=26)$ with $\mathrm{T} 2 \mathrm{D}$ in London so that the health states and methods could be refined for clarity and ease of administration.

Each health state was presented on an individual card with descriptions in bullet points. The first health state (health state A, the "basic health state") described a patient with $\mathrm{T} 2 \mathrm{D}$ receiving oral treatment. This health state, with language adapted from previous studies, provided context for the injection-related attributes that were included in the other health states. ${ }^{20,21}$

Six subsequent health states (B to G, the "injectable health states") had the same content as health state A, but added description of a weekly injectable treatment with additional statements describing three injection process attributes: reconstitution, waiting, and needle handling. To provide respondents with a clear understanding of these injection process attributes, a device display page was also presented. This page described and illustrated characteristics of an injection pen and the three injection process attributes. The text was based on the instructions for use of each injection pen, and the illustrations were taken from these instructions..$^{27-29}$

Development of text for these three injection-related attributes has been described in detail previously. ${ }^{11}$ The full text of the English version of health state A and the device display page is included in the previously published article. ${ }^{11}$ All materials are available from the authors upon request, including the original English health states and device display page, as well as the translated Italian versions. It was hypothesized that some participants would prefer health states without the requirements for reconstitution, waiting time during medication preparation, and needle handling.

\section{Participants}

To be eligible for inclusion in the study, participants were required to 1) be diagnosed with diabetes by a recognized medical professional; 2) be between the ages of 30 and 75 years old; 3 ) have T2D as indicated by patient report of diagnosis, current or previous non-insulin medication treatment for diabetes, and/or age of diagnosis; 4) be able to understand the assessments as judged by the investigator; 5) be a resident of Italy; and 6) be willing and able to give informed consent. Participants were not eligible if they had type 1 diabetes, latent autoimmune diabetes in adults (LADA), cognitive impairment, hearing difficulty, or severe pathology that could interfere with their ability to complete the interview. All participants were required to verify their diagnosis of T2D in one of two ways. Participants who were currently receiving medication treatment for T2D were required to bring proof of this medication to the interviews (eg, medication packaging or a letter from a doctor). Participants who were not receiving medication were required to describe their symptom history, diagnosis process, and disease management strategies in a way that clearly indicated that they were honestly reporting their diagnosis.

Participants were recruited in compliance with Italian privacy law (Legislative Decree no 196 of 30 June 2003 [Codice in materia di protezione dei dati personali, the "Privacy Code"]). Patients were recruited from a database of patients who participated in previous studies and expressed interest in being contacted for future studies. Each patient was originally contacted and added to the database by a network of recruiters who work for a market research company. For the current study, participants were contacted via telephone or e-mail, depending on their preferred contact method listed in the database. In addition to strictly adhering to the inclusion criteria described earlier, several recruitment targets were used to ensure that no particular demographic group was over-represented: maximum $60 \%$ of either men or women, maximum $10 \%$ unemployed, maximum $50 \%$ retired (the maximum for retired participants was relatively high because the population of patients with T2D tends to be older on average). A total of 450 patients were screened to assess whether they met the inclusion criteria, and 157 of these did not meet criteria. Of the 293 who were eligible, 241 were scheduled, and 240 attended their interviews. Two of the 240 participants had difficulty understanding the utility interview procedures and health states, and were therefore unable to provide valid data. Thus, a total of 238 (120 Rome, 118 Milan) valid interviews were completed.

\section{Translation}

Study materials were translated into Italian for use in this study. The translation process for study materials other than the health states (eg, device display page, standardized interview guide, consent form, demographic form) consisted of the following steps. First, the initial translation from English to Italian was conducted by a native Italian speaker. Then, an additional translator who is a native Italian speaker and was not involved in the forward translation reviewed the translation and performed editing and proofreading of the Italian version in conjunction with trained translation project managers. Finally, Italian members of the study team and data 
collection staff reviewed all Italian documents and recommended final edits to ensure that the materials would be clear and comprehensible to Italian-speaking study participants.

Translation of the health states followed the same methodology, but with an additional back-translation step. This back translation was performed by a native English speaker fluent in Italian, and it was reviewed by an additional translator who is a native Italian speaker (but who was not involved in the forward translation) in conjunction with trained translation project managers.

\section{Utility interview procedures and scoring}

Health state utilities were elicited in a valuation study conducted in March and April 2017 in two locations in Italy: Milan and Rome. All participants provided written informed consent. The study protocol was approved by an independent institutional review board (Ethical \& Independent Review Services; Study Number 17011-01). Each one-on-one interview was conducted in a quiet private room by one of five Italian-speaking interviewers. The TTO utility assessment followed a semi-structured interview script in order to standardize the utility assessment procedures. The principal investigator (who also directed the original UK study on which this study was based) trained the interviewers and observed each interviewer multiple times to ensure that procedures were followed consistently.

Utility interview procedures were the same as those previously described for the UK study. ${ }^{11}$ In each interview, the basic health state describing T2D treated with oral medication (health state A) was presented first. Then, the device display page was presented to introduce the injection device attributes. After participants indicated that they understood these injection device attributes, the six health states describing treatment with injectable medication (B to $G$ ) were presented in random order. Then, participants ranked the health states from most preferable to least preferable.

After the introductory ranking task was completed, participants valued the health states in a TTO task with a 20-year time horizon and 1-year (ie, 5\%) trading increments. Following commonly used TTO procedures, ${ }^{3}$ participants were asked which of two options they would prefer: 20 years in the health state being rated or a shorter amount of time in full health. The amount of time in full health alternated between longer and shorter time periods (ie, 20 years, 0 years [ie, dead], 19 years, 1 year, 18 years, 2 years, 17 years, 3 years...). The utility value of each health state was calculated as $u=x / y$ based on the point of indifference between $y$ years in the health state being evaluated (ie, 20 years) and $x$ years in full health (followed by dead).

\section{EQ-5D-3L}

The EQ-5D-3L was administered to characterize the sample in terms of overall health status. The EQ-5D is a self-administered, generic, preference-weighted measure of health status. ${ }^{30-32}$ The first section consists of five dimensions to assess health-related quality of life (mobility, self-care, usual activities, pain/discomfort, and anxiety/depression). These five dimensions are scored based on preference weightings to obtain an "index score" that is often used as a utility in economic modeling. The second section consists of a visual analog scale on which respondents rate their current health, with anchors of 0 (worst imaginable health state) and 100 (best imaginable health state). The EQ-5D-3L index score was computed using published Italian tariffs. ${ }^{33}$

\section{Statistical analysis procedures}

Statistical analyses were completed using SAS version 9.4 (SAS Institute, Cary, NC, USA). Descriptive statistics were calculated for continuous variables (means and standard deviations) and categorical variables (frequencies and percentages). Demographic subgroups were compared with chisquare analyses (for categorical variables) and independent $t$-tests (for continuous variables). Pairwise comparisons between health state utilities were performed using Student's $t$-tests. For each injection process attribute, disutilities (ie, decreases or differences in utility) were calculated by subtracting mean utility scores. Independent $t$-tests were also used to compare utilities between demographic subgroups (eg, gender, age), as well as between the current Italian sample and the previous UK sample.

\section{Results}

\section{Sample description}

Interviews were completed by a total of 238 participants with T2D, including 120 in Rome and 118 in Milan (Table 1). At the time of their interviews, the majority of respondents were treated with oral medication for T2D (n $=170,71.4 \%)$. Fewer patients were receiving injectable medication $(n=18,7.6 \%)$, combined oral/injectable treatment regimens $(n=40,16.8 \%)$, or no medication $(n=10$, $4.2 \%$ ). Of the 238 participants, 228 brought proof of current medication to the interviews. The other 10 participants who were not taking medication described their symptoms, diagnosis, and treatment at a level of detail indicating that they were accurately reporting their diagnoses. The most commonly reported comorbid health conditions were hypertension (46\%); diabetic retinopathy (11\%); anxiety (13\%); heart attack or heart disease (11\%); and arthritis (10\%). 
Table I Demographic characteristics

\begin{tabular}{|c|c|c|c|c|}
\hline Characteristics & $\begin{array}{l}\text { Rome } \\
(\mathbf{N}=\mid 20)\end{array}$ & $\begin{array}{l}\text { Milan } \\
(\mathbf{N}=|| \mathbf{8})\end{array}$ & $\begin{array}{l}\text { Participants in the } \\
\text { analysis sample } \\
(\mathbf{N}=\mathbf{2 3 8})\end{array}$ & $p$-value ${ }^{a}$ \\
\hline Age (mean, SD) & $60.8(9.2)$ & $59.7(9.5)$ & $60.2(9.3)$ & 0.362 \\
\hline Gender (n, \%) & & & & 0.676 \\
\hline Male & $69(57.5)$ & $71(60.2)$ & $140(58.8)$ & \\
\hline Female & $51(42.5)$ & $47(39.8)$ & $98(4 \mid .2)$ & \\
\hline \multicolumn{5}{|l|}{ Ethnicity (n, \%) } \\
\hline White & $120(100.0)$ & $118(100.0)$ & $238(100.0)$ & \\
\hline Marital status (n, \%) & & & & 0.963 \\
\hline Single & $7(5.8)$ & $6(5.1)$ & $13(5.5)$ & \\
\hline Married/living with partner & $79(65.8)$ & $79(66.9)$ & $158(66.4)$ & \\
\hline Other & $34(28.3)$ & $33(28.0)$ & $67(28.2)$ & \\
\hline \multicolumn{5}{|l|}{ Employment status ${ }^{\mathrm{b}}(\mathrm{n}, \%)$} \\
\hline Full-time work & $37(30.8)$ & $50(42.4)$ & $87(36.6)$ & 0.065 \\
\hline Part-time work & $12(10.0)$ & $15(12.7)$ & $27(11.3)$ & 0.510 \\
\hline Homemaker/housewife & $16(13.3)$ & $5(4.2)$ & $21(8.8)$ & 0.013 \\
\hline Unemployed & $9(7.5)$ & $6(5.1)$ & $15(6.3)$ & 0.443 \\
\hline Retired & $45(37.5)$ & $46(39.0)$ & $91(38.2)$ & 0.814 \\
\hline Disabled & $2(1.7)$ & $2(1.7)$ & $4(1.7)$ & 0.986 \\
\hline Education level, grouped (n, \%) & & & & 0.653 \\
\hline University degree & $13(10.8)$ & $15(12.7)$ & $28(1 \mathrm{I} .8)$ & \\
\hline No university degree & $107(89.2)$ & $103(87.3)$ & $210(88.2)$ & \\
\hline
\end{tabular}

Notes: ${ }^{a} p$-values comparing between Rome and Milan are based on independent $t$-tests for continuous variables and chi-square tests for categorical variables; ${ }^{b}$ not mutually exclusive.

Independent $t$-tests revealed that there were no statistically significant differences in utility or disutility between men and women; between older and younger respondents (categorized by median split); or among treatment regimen groups (analysis of variance [ANOVA] comparing no medication, oral only, and injectable with or without oral medication).

The EQ-5D-3L mean index score was $0.91(\mathrm{SD}=0.12)$ when computed with published Italian EQ-5D tariffs. ${ }^{33}$ This mean is slightly higher than most scores published previously for patients with T2D without complications, ${ }^{34}$ likely because the Italian tariffs yield higher index scores than the more commonly used UK tariffs.

\section{Health state utilities}

When ranking the seven health states, respondents generally placed them in a logical order. Health states describing more inconveniences associated with the injection device were typically ranked as less preferable. Rankings ranged from 1 (most preferable health state) to 7 (least preferable health state). The oral-only health state (A) was always ranked as most preferable (mean ranking of 1.00), followed by $\mathrm{G}$ (2.07), F (3.57), E (3.65), D (5.18), C (5.60), and B (6.94).

The utility scores followed a similar pattern to the ranking, with injection-related inconveniences associated with lower utility (Table 2). The mean utility for health state A (representing diabetes with oral treatment and no injection)

Table 2 Utilities and disutilities

\begin{tabular}{|c|c|c|c|c|c|c|}
\hline \multirow[t]{2}{*}{ Health states } & \multirow[t]{2}{*}{$\begin{array}{l}\text { Mean } \\
\text { utility }^{\mathrm{a}}\end{array}$} & \multirow[t]{2}{*}{ (SD) } & \multicolumn{2}{|c|}{$\begin{array}{l}\text { Disutilities: } \\
\text { difference from } \\
\text { health state A }\end{array}$} & \multicolumn{2}{|c|}{$\begin{array}{l}\text { Disutilities: } \\
\text { difference from } \\
\text { health state G }\end{array}$} \\
\hline & & & Mean & (SD) & Mean & (SD) \\
\hline A. Basic health state (oral treatment only) & 0.900 & $(0.097)$ & - & - & - & - \\
\hline \multicolumn{7}{|c|}{ Health states with oral and injectable treatment ${ }^{b}$} \\
\hline B. Reconstitution, waiting, needle handling & 0.868 & $(0.109)$ & -0.032 & $(0.059)$ & -0.022 & $(0.052)$ \\
\hline C. Reconstitution, waiting & 0.872 & $(0.109)$ & -0.027 & $(0.058)$ & -0.018 & $(0.052)$ \\
\hline D. Reconstitution, needle handling & 0.879 & $(0.102)$ & -0.020 & $(0.040)$ & -0.011 & $(0.030)$ \\
\hline E. Reconstitution & 0.884 & $(0.100)$ & -0.015 & $(0.032)$ & -0.006 & $(0.02 I)$ \\
\hline F. Needle handling & 0.884 & $(0.101)$ & -0.016 & $(0.033)$ & -0.006 & $(0.021)$ \\
\hline G. No inconveniences & 0.890 & $(0.100)$ & -0.009 & $(0.025)$ & - & - \\
\hline
\end{tabular}

Notes: aTTO scores are on a scale anchored with 0 representing dead and I representing full health; bhealth states B to $G$ include the basic health state, plus treatment with a weekly injection.

Abbreviation: TTO, time trade-off. 
was 0.900 . The addition of a weekly injection in health state $\mathrm{G}$ reduced utility to 0.890 . The addition of treatment process inconveniences associated with the weekly injection decreased utility further. The lowest utility value was for health state $\mathrm{B}$, which described all three injection-related conveniences: reconstitution, waiting, and needle handling (0.868). All participants rated every health state as better than dead, and therefore, there were no negative utility values.

\section{Disutilities and comparisons among health states}

Disutility scores (ie, decreases in utility) are provided relative to health state A describing oral-only treatment and relative to health state $\mathrm{G}$ describing oral plus weekly injectable treatment (Table 2). The disutility of each injection process attribute (ie, reconstitution, waiting, needle handling) was calculated by subtracting health state $G$ from health states B to F. For example, the disutility of the needle handling requirement was calculated as the difference between $\mathrm{G}$ and $\mathrm{F}(-0.006)$, two health states that were identical except for the addition of needle handling. Each individual injection attribute had a relatively small disutility (eg, disutility $=-0.006$ ). However, larger disutilities were found for health states that included multiple injection-related inconveniences, such as health state B representing the combination of reconstitution, waiting, and needle handling requirements (disutility $=-0.022$ ).

Student's $t$-tests revealed that the utility of the oral-only health state (health state A) was statistically significantly greater than the utility of every other health state (all $p<0.0001)$. In addition, the injection health state without any of the three inconveniences (health state $G$ ) was compared to each of the other injection health states (B to F). The utility of $\mathrm{G}$ was found to be significantly greater than the utility of all health states that included reconstitution, waiting, and/or mixing (all $p<0.0001$ ).

\section{Geographical comparisons}

Independent $t$-tests found no significant differences in mean utility or disutility between the UK sample in the original study ${ }^{11}$ and the Italian sample in this replication study (Tables 3 and 4). Utilities and disutilities were also compared between the two cities in Italy, and the relationships among health states were almost identical in the two cities. There were no significant differences between the two cities in disutility associated with injection-device attributes (ie, the difference score when subtracting the utility of health state $\mathrm{G}$ from the utility of the other injection health states), and difference in disutility between the two cities was 0.00 for all health states (ie, identical disutilities in Milan and Rome to two decimal places). However, mean utility values for each health state were greater in Milan than in Rome (all $p<0.01$ ). The mean utility in Milan was greater than Rome by a magnitude of 0.04 for health state A and a magnitude of 0.05 for all other health states. For example, utilities of health states B, D, and G were $0.84,0.85$, and 0.87 in Rome, compared with $0.89,0.91$, and 0.92 , respectively, in Milan. Thus, the pattern of mean scores was the same in the two cities, indicating similar preference among injection device characteristics, but the lower utility scores in Rome suggest greater willingness to trade time regardless of health state.

\section{Discussion}

In this replication study in Italy, patient preferences for attributes of weekly GLP-1 receptor agonist injections were consistent with those in the original UK study. ${ }^{11}$ As in the UK study, each individual injection inconvenience (reconstitution, waiting, needle handling) had a relatively small impact on utility $(-0.006$ to -0.011$)$, but health states representing

Table 3 t-tests comparing TTO scores between countries (Italy vs UK $\left.{ }^{\mathrm{a}}\right)(\mathrm{N}=447)$

\begin{tabular}{|c|c|c|c|c|c|}
\hline \multirow[t]{2}{*}{ Health state ${ }^{b}$ utilities } & \multirow{2}{*}{$\begin{array}{l}\begin{array}{l}\text { Italy } \\
(\mathrm{n}=238)\end{array} \\
\text { Mean (SD) }\end{array}$} & \multirow{2}{*}{$\begin{array}{l}\text { UK } \\
(n=209) \\
\text { Mean (SD) }\end{array}$} & \multirow{2}{*}{$\begin{array}{l}\text { Difference } \\
\text { between Italy } \\
\text { and the UK } \\
\text { Mean (SD) }\end{array}$} & \multicolumn{2}{|l|}{ t-test } \\
\hline & & & & $t$-statistic & p-value \\
\hline A. Oral treatment only & $0.900(0.097)$ & $0.888(0.120)$ & $0.012(0.108)$ & 1.132 & 0.258 \\
\hline \multicolumn{6}{|c|}{ Health states with oral and injectable treatment } \\
\hline B. Reconstitution, waiting, needle handling & $0.868(0.109)$ & $0.858(0.165)$ & $0.010(0.138)$ & 0.779 & 0.437 \\
\hline C. Reconstitution, waiting & $0.872(0.109)$ & $0.863(0.161)$ & $0.009(0.136)$ & 0.681 & 0.496 \\
\hline D. Reconstitution, needle handling & $0.879(0.102)$ & $0.868(0.159)$ & $0.011(0.132)$ & 0.885 & 0.377 \\
\hline E. Reconstitution & $0.884(0.100)$ & $0.874(0.157)$ & $0.010(0.130)$ & 0.804 & 0.422 \\
\hline F. Needle handling & $0.884(0.101)$ & $0.874(0.156)$ & $0.010(0.130)$ & 0.781 & 0.435 \\
\hline G. No inconveniences & $0.890(0.100)$ & $0.878(0.156)$ & $0.012(0.129)$ & 0.989 & 0.323 \\
\hline
\end{tabular}

Notes: aUK data adapted with permission from Matza LS, Boye KS, Stewart KD, Davies EW, Paczkowski R. Health state utilities associated with attributes of weekly injection devices for treatment of type 2 diabetes. BMC Health Serv Res. 2017;17:774;"' bhealth states B to G include health state A, plus treatment with a weekly injection. Independent $t$-tests were used.

Abbreviation: TTO, time trade-off. 
Table 4 t-tests comparing TTO disutility scores between countries (Italy vs UKa) $(N=447)$

\begin{tabular}{|c|c|c|c|c|c|}
\hline \multirow[t]{2}{*}{ 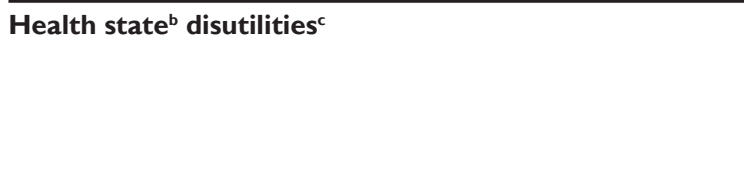 } & \multirow{2}{*}{$\begin{array}{l}\text { Italy } \\
(n=238) \\
\text { Mean (SD) }\end{array}$} & \multirow{2}{*}{$\begin{array}{l}\text { UK } \\
(n=209) \\
\text { Mean (SD) }\end{array}$} & \multirow{2}{*}{$\begin{array}{l}\text { Difference } \\
\text { between Italy } \\
\text { and the UK } \\
\text { Mean (SD) }\end{array}$} & \multicolumn{2}{|l|}{ t-test } \\
\hline & & & & t-statistic & p-value \\
\hline \multicolumn{6}{|l|}{ Disutilities relative to health state $\mathbf{A}$} \\
\hline $\begin{array}{l}\text { A vs B: Oral treatment only vs reconstitution, waiting, } \\
\text { needle handling }\end{array}$ & $-0.032(0.059)$ & $-0.030(0.073)$ & $-0.001(0.066)$ & -0.212 & 0.832 \\
\hline A vs C: Oral treatment only vs reconstitution, waiting & $-0.027(0.058)$ & $-0.025(0.066)$ & $-0.003(0.062)$ & -0.474 & 0.636 \\
\hline A vs D: Oral treatment only vs reconstitution, needle handling & $-0.020(0.040)$ & $-0.020(0.063)$ & $-0.000(0.052)$ & -0.082 & 0.935 \\
\hline A vs $\mathrm{E}:$ Oral treatment only vs reconstitution & $-0.015(0.032)$ & $-0.014(0.058)$ & $-0.002(0.046)$ & -0.343 & 0.732 \\
\hline A vs F: Oral treatment only vs needle handling & $-0.016(0.033)$ & $-0.014(0.058)$ & $-0.002(0.047)$ & -0.411 & 0.681 \\
\hline A vs G: Oral treatment only vs no inconveniences & $-0.009(0.025)$ & $-0.010(0.056)$ & $0.001(0.042)$ & 0.167 & 0.867 \\
\hline \multicolumn{6}{|l|}{ Disutilities relative to health state G } \\
\hline $\begin{array}{l}\text { G vs B: No inconveniences vs reconstitution, waiting, } \\
\text { needle handling }\end{array}$ & $-0.022(0.052)$ & $-0.020(0.042)$ & $-0.002(0.048)$ & -0.455 & 0.649 \\
\hline G vs C: No inconveniences vs reconstitution, waiting & $-0.018(0.052)$ & $-0.014(0.032)$ & $-0.003(0.044)$ & -0.865 & 0.388 \\
\hline G vs D: No inconveniences vs reconstitution, needle handling & $-0.011(0.030)$ & $-0.010(0.027)$ & $-0.00 \mathrm{I}(0.029)$ & -0.412 & 0.681 \\
\hline G vs $E:$ No inconveniences vs reconstitution & $-0.006(0.021)$ & $-0.004(0.016)$ & $-0.002(0.019)$ & -1.281 & 0.201 \\
\hline G vs F: No inconveniences vs needle handling & $-0.006(0.021)$ & $-0.004(0.015)$ & $-0.003(0.018)$ & -1.512 & 0.131 \\
\hline
\end{tabular}

Notes: aUK data adapted with permission from Matza LS, Boye KS, Stewart KD, Davies EW, Paczkowski R. Health state utilities associated with attributes of weekly injection devices for treatment of type 2 diabetes. BMC Health Serv Res. 2017;17:774;"' bhealth states B to G include health state A, plus treatment with a weekly injection; 'disutilities computed for "A. Oral only" as $\mathrm{x}-\mathrm{A}$; and for "G. No inconveniences (Dulaglutide)" as $\mathrm{x}-\mathrm{G}$. Independent $t$-tests were used.

Abbreviation: TTO, time trade-off.

simultaneous multiple inconveniences were associated with greater disutility (up to -0.022 for all three inconveniences combined in health state B). The mean disutility scores for the injection device attributes estimated in this Italian sample were nearly identical to those in the UK sample. These disutilities are similar in magnitude to utility differences reported for other treatment process variables, such as route of administration and variations in the injection process, which typically range from 0.01 to $0.05 .{ }^{20,35,36}$ These small differences in utility can have an impact on the outcome of a cost-utility model, particularly when modeling large groups of patients over a long time period. Thus, the current utility values may be useful for representing patient preferences in economic models of weekly GLP-1 receptor agonists for T2D in Italy. In addition, the utilities could potentially be applicable in models of other medications that are administered with similar injection devices.

As with results of the UK study, ${ }^{11}$ researchers working on cost-utility models comparing weekly GLP-1 receptor agonists should focus primarily on differences among health states B through G (the column titled "Disutilities: Difference from Health State G" in Table 2). Because these six health states are identical except for differences in the three injection attributes, any differences in utility can be attributed specifically to these three attributes (ie, reconstitution, waiting, needle handling). For example, a model could compare cost-effectiveness in Italy of a medication requiring needle handling to a medication without this requirement. In this situation, the utility difference between health states $\mathrm{F}$ and $\mathrm{G}$ would be relevant, and the corresponding disutility of -0.006 may be applied to the treatment arm representing the injection pen with the needle handling requirement.

Despite the similarity in mean disutility scores between Italy and the UK, an interesting geographical difference within Italy did emerge. The key results of the study are the disutilities associated with each of the three injection-related attributes, and these disutility values were nearly identical in the Milan and Rome groups (and also very similar to results from the original UK sample). However, while the pattern of differences among health states was the same across the two Italian cities, the mean utility of each individual health state was greater in Milan than in Rome by a consistent magnitude for all health states (ie, difference of 0.05 for all injection health states). These results indicate that while preferences among injection-related attributes were consistent across the cities, there may be geographical differences in willingness to trade time in a TTO task. On average, respondents in Rome were willing to trade more time than respondents in Milan, resulting in lower utilities in Rome. While this difference in trading style had no apparent impact on the disutilities of the treatment-related attributes, which were consistent across the two cities, it may be useful for future research to examine demographic or geographic differences in willingness to trade time. 


\section{Limitations}

An important limitation of this research is that disutilities of the injection process attributes are based on patients' interpretations of hypothetical health state vignettes, rather than personal experience with each injection device. Vignettebased utilities should be interpreted and used with caution because this methodology could be subject to biases. For example, preferences expressed during the TTO task could be influenced by a focusing effect, causing respondents to attend closely to small differences among health states and potentially exaggerating differences in utility.

Furthermore, comparability of utilities estimated via vignette-based methods to utilities derived from more standardized approaches such as the EQ-5D is uncertain. Some health technology assessment guidelines, particularly the guide issued by National Institute for Health and Care Excellence, indicate a preference for generic preference-based utility measures such as the EQ-5D to maximize "consistency across appraisals." ${ }^{26}$ This guide adds that utilities estimated using other methods may be useful when the EQ-5D is not "appropriate." ${ }^{26}$ Estimation of utilities associated with treatment process is one situation when the EQ-5D is not likely to be appropriate because generic instruments such as the EQ-5D may not be sensitive to specific treatment-related attributes. The vignette approach is a useful alternative for assessment of treatment process utilities because vignettes can be designed to differ based on specific treatment process attributes. This is likely why the great majority of studies on "process utilities" use vignette-based methods despite the challenges in comparing results to generic measures such as the EQ-5D. ${ }^{35}$

\section{Conclusion}

Despite limitations, findings add to the growing body of literature suggesting that the treatment process has a measurable impact on patient preference and health state utility, ${ }^{35,37,38}$ particularly among patients with T2D..$^{20,21,39}$ The current study builds on this previous research by quantifying patient preferences for some key injection-related attributes of weekly GLP-1 receptor agonists. In addition to providing further insight into patient preferences, the resulting utility scores may be useful in economic modeling of these treatments. The similarity between the results from this Italian replication and the original UK study supports confidence in these findings, indicating that patient preferences were consistent despite geographical, cultural, and linguistic differences. In a larger sense, this consistency between the two geographic locations provides initial support for using UK utility values as inputs in cost-utility models in Italy. Additional utility elicitation research in Italy and other locations is needed to further examine generalizability of patient preferences and utilities across geographic regions.

\section{Acknowledgments}

This study was funded by Eli Lilly and Company (Indianapolis, IN, USA). The authors would like to thank staff members from G\&G Associated (Flavia Severin and Marina Deiana) for assistance with patient recruitment and data collection; Gianfranco Salvi and Nuria Uggetti for assistance with data collection; study interviewers (Paula Matte Bon, Valeria Carlodalatri, David Vittoria, Cristina Mazzoletti, Manuela Re); Benjamin Arnold and the FACITtrans team for performing the translations; Julie McCormack for assistance with data collection forms; and Ren Yu for statistical programming. Parts of this paper were included in a poster presentation at the International Society For Pharmacoeconomics and Outcomes Research 19th Annual European Congress, October 29 to November 2, 2016 in Vienna, Austria: https://www.ispor. org/ScientificPresentationsDatabase/Presentation/58898.

\section{Disclosure}

This study was funded by Eli Lilly and Company (Indianapolis, IN, USA). Five of the study authors are employed by the sponsor: KS Boye, K Norrbacka, R Gentilella, M Orsini Federici, and G Biricolti. Five of the authors are employed by Evidera, a company that received funding from Lilly for time spent conducting this research: LS Matza, J Jordan, A Tiebout, C Browne, and KD Stewart. The authors report no other conflicts of interest in this work.

\section{References}

1. Feeny D. Preference-based measures: utility and quality-adjusted life years. In: Fayers P, Hays R, editors. Assessing Quality of Life in Clinical Trials. 2nd ed. New York: Oxford University Press; 2005:405-431.

2. Torrance GW. Measurement of health state utilities for economic appraisal. J Health Econ. 1986;5:1-30.

3. Brazier JR, Ratcliffe J, Salomon JA, Tsuchiya A. Measuring and Valuing Health Benefits for Economic Evaluation. New York: Oxford University Press; 2007.

4. Fusco F, Turchetti G. Telerehabilitation after total knee replacement in Italy: cost-effectiveness and cost-utility analysis of a mixed telerehabilitation-standard rehabilitation programme compared with usual care. BMJ Open. 2016;6:e09964.

5. Marcellusi A, Viti R, Russo S, Andreoni M, Antinori A, Mennini FS. Early treatment in HIV patients: a cost-utility analysis from the Italian perspective. Clin Drug Investig. 2016;36:377-387.

6. Ruggeri M, Basile M, Coretti S, Drago C, Cicchetti A. Economic analysis and budget impact of tenofovir and entecavir in the first-line treatment of hepatitis B virus in Italy. Appl Health Econ Health Policy. 2017; 15:479-490.

7. Sullivan SD, Craxi A, Alberti A, et al. Cost effectiveness of peginterferon alpha-2a plus ribavirin versus interferon alpha- $2 \mathrm{~b}$ plus ribavirin as initial therapy for treatment-naive chronic hepatitis C. Pharmacoeconomics. 2004;22:257-265. 
8. Chevreul K, Gandre C, Brigham KB, et al. Social/economic costs and health-related quality of life in patients with fragile $\mathrm{X}$ syndrome in Europe. Eur J Health Econ. 2016;17(Suppl 1):43-52.

9. Kerr C, Lloyd EJ, Kosmas CE, et al. Health-related quality of life in Parkinson's: impact of “off” time and stated treatment preferences. Qual Life Res. 2016;25:1505-1515.

10. Mozzi A, Meregaglia M, Lazzaro C, Tornatore V, Belfiglio M, Fattore G. A comparison of EuroQol 5-Dimension health-related utilities using Italian, UK, and US preference weights in a patient sample. Clinicoecon Outcomes Res. 2016;8:267-274.

11. Matza LS, Boye KS, Stewart KD, Davies EW, Paczkowski R. Health state utilities associated with attributes of weekly injection devices for treatment of type 2 diabetes. BMC Health Serv Res. 2017;17:774.

12. Aroda VR, Henry RR, Han J, et al. Efficacy of GLP-1 receptor agonists and DPP-4 inhibitors: meta-analysis and systematic review. Clin Ther. 2012;34:1247.e22-1258.e22.

13. Aroda VR, Ratner R. The safety and tolerability of GLP-1 receptor agonists in the treatment of type 2 diabetes: a review. Diabetes Metab Res Rev. 2011;27:528-542.

14. Inzucchi SE, Bergenstal RM, Buse JB, et al. Management of hyperglycemia in type 2 diabetes: a patient-centered approach: position statement of the American Diabetes Association (ADA) and the European Association for the Study of Diabetes (EASD). Diabetes Care. 2012; 35:1364-1379.

15. NICE. Type 2 diabetes: the management of type 2 diabetes. NICE Clinical Guideline 87. London, UK. Issued: May 2009, Last Modified: December 2014:54.

16. Tran L, Zielinski A, Roach AH, et al. Pharmacologic treatment of type 2 diabetes: injectable medications. Ann Pharmacother. 2015; 49:700-714

17. Trujillo JM, Nuffer W, Ellis SL. GLP-1 receptor agonists: a review of head-to-head clinical studies. Ther Adv Endocrinol Metab. 2015;6: 19-28.

18. European Agency for Safety and Health at Work. Directive 2010/32/ $\mathrm{EU}$ - prevention from sharp injuries in the hospital and healthcare sector. May 2010. Available from: https://osha.europa.eu/en/legislation/directives/council-directive-2010-32-eu-prevention-from-sharp-injuries-inthe-hospital-and-healthcare-sector. Accessed January 13, 2016.

19. Health and Safety Executive. Health and Safety (Sharp Instruments in Healthcare) Regulations 2013 - Guidance for employers and employees. London, UK: Health and Safety Executive (HSE); 2013:6.

20. Boye KS, Matza LS, Walter KN, Van Brunt K, Palsgrove AC, Tynan A. Utilities and disutilities for attributes of injectable treatments for type 2 diabetes. Eur J Health Econ. 2011;12:219-230.

21. Matza LS, Boye KS, Yurgin N, et al. Utilities and disutilities for type 2 diabetes treatment-related attributes. Qual Life Res. 2007;16: 1251-1265.

22. Beaudet A, Palmer JL, Timlin L, et al. Cost-utility of exenatide once weekly compared with insulin glargine in patients with type 2 diabetes in the UK. J Med Econ. 2011;14:357-366.

23. Mittendorf T, Smith-Palmer J, Timlin L, Happich M, Goodall G. Evaluation of exenatide vs. insulin glargine in type 2 diabetes: costeffectiveness analysis in the German setting. Diabetes Obes Metab. 2009;11:1068-1079.
24. Samyshkin Y, Guillermin AL, Best JH, Brunell SC, Lloyd A. Long-term cost-utility analysis of exenatide once weekly versus insulin glargine for the treatment of type 2 diabetes patients in the US. J Med Econ. 2012;15(Suppl 2):6-13.

25. Sinha A, Rajan M, Hoerger T, Pogach L. Costs and consequences associated with newer medications for glycemic control in type 2 diabetes. Diabetes Care. 2010;33:695-700.

26. NICE (National Institute for Health and Care Excellence). Process and Methods Guides: Guide to the Methods of Technology Appraisal 2013. London, UK: NICE; 2013.

27. AstraZeneca Pharmaceuticals. Instructions for use-Bydureon SingleDose Tray (exenatide extended-release) for injectable suspension. 13-26, 2014. Available from: http:/www.azpicentral.com/bydureon/ ifu_bydureon.pdf\#page=1. Accessed May 4, 2015.

28. Eli Lilly and Company. Instructions for use: TRULICITY (dulaglutide) injection, for subcutaneous use $1.5 \mathrm{mg} / 0.5 \mathrm{~mL}$ Single-Dose Pen once weekly. 2015. Available from: http://pi.lilly.com/us/trulicity-highdoseai-ifu.pdf. Accessed May 4, 2015.

29. GlaxoSmithKline (GSK). Highlights of prescribing information: Tanzeum (albiglutide) for injection, for subcutaneous use. 1-56, 2015. Available from: https:/www.gsksource.com/pharma/content/ dam/GlaxoSmithKline/US/en/Prescribing_Information/Tanzeum/pdf/ TANZEUM-PI-MG-IFU-COMBINED.PDF. Accessed May 5, 2015.

30. Brooks R. EuroQol: the current state of play. Health Policy. 1996;37: 53-72.

31. Herdman M, Gudex C, Lloyd A, et al. Development and preliminary testing of the new five-level version of EQ-5D (EQ-5D-5L). Qual Life Res. 2011;20:1727-1736.

32. The EuroQol Group. EuroQol - a new facility for the measurement of health-related quality of life. Health Policy. 1990;16:199-208.

33. Scalone L, Cortesi PA, Ciampichini R, et al. Italian population-based values of EQ-5D health states. Value Health. 2013;16:814-822.

34. Janssen MF, Lubetkin EI, Sekhobo JP, Pickard AS. The use of the EQ-5D preference-based health status measure in adults with Type 2 diabetes mellitus. Diabet Med. 2011;28:395-413.

35. Brennan VK, Dixon S. Incorporating process utility into quality adjusted life years: a systematic review of empirical studies. Pharmacoeconomics. 2013;31:677-691.

36. Matza LS, Sapra SJ, Dillon JF, et al. Health state utilities associated with attributes of treatments for hepatitis C. Eur J Health Econ. 2015;16: 1005-1018.

37. Hixson-Wallace JA, Dotson JB, Blakey SA. Effect of regimen complexity on patient satisfaction and compliance with warfarin therapy. Clin Appl Thromb Hemost. 2001;7:33-37.

38. Raue PJ, Schulberg HC, Heo M, Klimstra S, Bruce ML. Patients' depression treatment preferences and initiation, adherence, and outcome: a randomized primary care study. Psychiatr Serv. 2009;60:337-343.

39. Polster M, Zanutto E, McDonald S, Conner C, Hammer M. A comparison of preferences for two GLP-1 products - liraglutide and exenatidefor the treatment of type 2 diabetes. J Med Econ. 2010;13:655-661.
Patient Preference and Adherence

\section{Publish your work in this journal}

Patient Preference and Adherence is an international, peer-reviewed, open access journal that focuses on the growing importance of patient preference and adherence throughout the therapeutic continuum. Patient satisfaction, acceptability, quality of life, compliance, persistence and their role in developing new therapeutic modalities and compounds to optimize

\section{Dovepress}

clinical outcomes for existing disease states are major areas of interest for the journal. This journal has been accepted for indexing on PubMed Central. The manuscript management system is completely online and includes a very quick and fair peer-review system, which is all easy to use. Visit http://www. dovepress.com/testimonials.php to read real quotes from published authors. 